\section{A QUESTÃO DA TRANSGRESSÃO \\ EM SADE E BATAILLE}

\section{Guilherme Grané Diniz}

Mestrando em Filosofia e Teoria Geral do

Direito

Universidade de São Paulo

\section{RESUMO}

O presente trabalho se propõe a realizar uma breve comparação entre $\mathrm{o}$ pensamento de Georges Bataille e do Marquês de Sade acerca da questão da transgressão. Neste sentido, aclararemos a leitura batailleana da obra de Sade, mostrando aproximações e distanciamentos entre ambos os autores. Mostraremos que Bataille incorporou de forma quase textual passagens e ideias presentes na obra de Sade, nem sempre se atendo ao sentido ou ao contexto no qual elas estavam postas. Procedendo a uma análise, primeiramente, de como o tema se põe na obra "O Erotismo", de Bataille, e então de como se apresenta em algumas obras principais de Sade, concluiremos que o principal ponto de contato entre ambos os autores, e a principal herança que Bataille recebeu de Sade, é o conceito de natureza.

Palavras-chave: Sade; Bataille; Transgressão; Natureza

\section{ABSTRACT \\ The presente paper aims to briefly compare the thoughts of french thinkers Georges Bataille and the Marquis de Sade regarding the question of transgression. Thus, we shall make clearer Bataille's Reading of the Works of De Sade, pointing to proximities and distances between both authors. We will show that Bataille has incorporated almost textually}

passages and ideias form De Sade's Works, not always considering their original sense and context. We will proceed by, firstly, analising how the theme is laid in George Bataille's "Death and Eroticism", and the how it is presented in certain central Works by De Sade. We will conclude that the main point of contact between both authors, and the main heritage Bataille gets from De Sade, is a peculiar concept of nature.

Key-words: Sade; Bataille; Transgression; Nature

Em sua introdução às obras completas de Georges Bataille, Michel Foucault faz uma afirmação muito interessante acerca da obra "O Erotismo". Diz ele que a obra "tornou Sade mais próximo de nós" (FOUCAULT apud BATAILLE, 1970, p. 1). Foi uma afirmação particularmente feliz, como pretendemos mostrar neste trabalho; de fato, existe uma forte semelhança de temas e abordagens entre as obras dos dois autores franceses. Decerto que também existem fortes divergências, e estas são capitais para compreensão das obras em sentido mais profundo, principalmente quando focamo-nos nas análises feitas por Bataille que se referem diretamente à obra de Sade. Em artigo dedicado a este tema, Geoffrey Roche (2006, p. 159) aponta que Bataille clama para si essa posição de herdeiro e continuador da obra de Sade, mas que mostra até mesmo certa má compreensão dela. Annie Le Brun (1984, p. 24), comentadora clássica da obra de 
Sade, por sua vez, afirma que a leitura de Bataille incorre no mesmo grave erro que parte significativa das leituras feitas à época: tenta fazer de Sade uma instância de sua própria teoria, desconsiderando os movimentos postos na própria obra; no caso, da noção de sacrifício e de sagrado. Ainda assim, no mesmo livro Le Brun (1984, p. 322) se vê obrigada a conceder que autores como Bataille e outros que ela critica foram capitais para a recepção de Sade em um século hostil. Neste breve texto, nos interessa mais observar este segundo aspecto da leitura batailleana, e, principalmente, em relação a um tema pontual, qual seja: aquilo que Bataille chama de transgressão.

Mais particularmente, como esta se mostra nas obras de Sade, o qual o precedeu, e como o filósofo incorporou e dialogou com o conceito, nos termos em que se poder falar nisto, que surge na obra literária. Este estudo particular nos revelará o ponto fulcral da relação teórica entre os dois autores: suas concepções de natureza.

Ainda em um caráter introdutório, devemos lembrar que os paralelos e comparações que aqui serão traçados não são simples do modo que eventualmente possa parecer. Isto porque existe, dentre outras, uma diferença radical entre as duas obras. Não sejamos ingênuos em crer que filosofia e literatura são compartimentos estanques e sem quaisquer relações.
Contudo, sem entrar no mérito de tão complexa e estimulante questão, assumiremos por um momento que tais gêneros são distintos e, mais do que isto, dificilmente comensuráveis.

Principalmente, o que queremos dizer é: o fato de Sade ter optado por expor seu pensamento em uma forma que não a filosófica tem sérias implicações no próprio conteúdo deste pensamento. Deste modo, é seriamente complexa a análise comparativa entre uma obra filosófica e outra literária, neste caso, principalmente em compreender como Bataille traz ideias expostas e concebidas artisticamente para dentro de um discurso filosófico. Isso, sem contar com um redobro significativo da questão: ambos os autores colocam em xeque aspectos formais da própria escrita.

Bataille tece fortes críticas à linguagem filosófica, especialmente àquela hegeliana. Habermas acredita poder mostrar uma séria incongruência em Bataille na medida em que este teria, por um lado, criticado a linguagem filosófica moderna, por outro se mostrado incapaz de se desvincular dela. Sem entrar no mérito de tal leitura, é evidente que em "O Erotismo" a questão posta e ao menos parte significativa da abordagem feita no sentido de respondê-la é hegeliana. Por outro lado, questiona-se comumente sobre o caráter literário da obra de Sade. Bataille mesmo considera que, se podemos dizer de 
Sade que escreve literatura, é de uma forma bastante imprópria.

De qualquer modo, uma primeira leitura que se faça dos dois autores já deixa claro como Sade e Bataille estão tratando de temas em comum. Mesmo algumas opções terminológicas são iguais. Porém, em momento algum encontraremos em Sade a expressão transgressão, ao menos em um sentido próximo ou parecido do que tem em Bataille; pode-se dizer deste que foi quem trouxe o conceito para contribuir com o debate acerca do assunto. Assim sendo, em vez de partirmos diretamente para a análise de como o Marquês trabalha esta questão e outras que a ela se ligam, mesmo que sob outros nomes, devemos buscar compreender conceitualmente o que Bataille entende por transgressão para então podermos melhor entender como esta se manifesta nas obras de Sade.

Bataille muito raramente nos concede definições precisas e exatas de seus termos ou define com precisão seus conceitos. Do erotismo, nos dá algumas "fórmulas". Uma, que o erotismo "é a aprovação da vida até na morte" (BATAILLE, 2013, p. 35), outra, que "o erotismo é, na consciência do homem, o que coloca o ser em questão" (BATAILLE, 2013, p. 56). A primeira coisa a ser ressaltada em ambas as formulações é uma certa oposição dualística entre vida e morte, consciência e inconsciência. Quando se fala nos limites do ser, em pôr o ser em questão, estamos tratando de uma experiência de desmesura que em partes se assemelha à própria morte, mas mais do que isto, falamos em uma experiência nos limites da racionalidade, conforme mostraremos mais à frente, mas que se localiza no seio da própria consciência. Esta oposição fundamental será por ele tratada como a oposição entre interdito e transgressão. Não pensemos, porém, que quando falamos em oposição dizemos simplesmente um embate ou antagonismo na qual um dos termos sobrepõe-se ao outro. $\mathrm{O}$ erotismo nasce de um movimento dialético bastante sutil, por meio do qual o interdito mantém-se presente e atuante, porém é superado pela transgressão (BATAILLE, 2013, p. 59) ${ }^{1}$

$\mathrm{Na}$ verdade, interdito e transgressão estão tão imbricados que a própria interposição do interdito já contém em si formas institucionalizadas de sua transgressão (BATAILLE, 2013, p. 89) (tomemos, por exemplo, o interdito do

1 O tema dialético é bastante relevante para Bataille, que o recebe dos cursos de Kojève. Para sintetizarmos de forma bastante breve uma questão complexa, o que está em jogo aqui é levar a dialética hegeliana a um ponto que mesmo Hegel não chegou: o reconhecimento da parte da consciência daquilo que é seu outro. Mesmo criticando Hegel e afirmando certa "insuficiência" em sua filosofia, Bataille ainda mantém a ideia de dialética, invocando-a diretamente. 
assassinato e sua transgressão institucionalizada, a guerra; ou o do incesto, que em certos contextos, principalmente religiosos, é incentivado), eles trabalham juntos em uma dinâmica na qual a própria proibição serve de incentivo para que se faça o proibido, e mesmo fazêlo não é capaz de pôr fim a esta proibição (BATAILLE, 2013, p. 72). É no seio deste movimento que surge o erotismo.

Para Sade, por sua vez, é muito relevante que a proibição ainda se faça sentir ao ser transgredida: é ela a fonte de gozo essencial para os personagens. O prazer do libertino não advém da mera fricção. Pelo contrário, depende fortemente da sensação da proibição que pesa contra suas ações. Os libertinos professam mil vezes seu ateísmo, mas não é por não crerem em Deus que deixam de blasfemalo. Eles notam essa contradição, mas seu lamento é muito peculiar: o libertino deseja que Deus exista para que suas blasfêmias tivessem um alvo mais concreto (SADE, 1989, p. 260). O que limita a ação do libertino não são as leis, mas a ausência delas: uma vez que não há Deus e a natureza é eminentemente má, tudo é permitido. Justamente por isso, não há verdadeiramente nenhum crime que se possa cometer, todos os crimes têm por alvo apenas as leis ilusórias e arbitrárias dos homens. Aqui, em germe, está justamente o esquema de Bataille: é a proibição que institui um campo de valores no qual o permitido e o proibido - e, por extensão, o sagrado e o profano, o tocável e o intocável, enfim, o erótico - ganham sentido e valor.

Um exemplo muito interessante disto encontra-se na obra "Os 120 Dias de Sodoma". O gozo dos libertinos depende da instituição de regras e limites para eles, de modo a impedir que seus excessos fiquem aquém ou além do desejado (SADE, 2006, p. 54). A obra começa com a longa narração do exaustivo percurso de quatro libertinos em direção a um castelo de tal modo isolado no cimo de uma montanha que nem os pássaros conseguem chegar. A primeira ação dos libertinos ao chegarem, enquanto as vítimas mesmas descansavam da extenuante viagem, foi criar um código legal que regulamentasse sua vida, inclusive a vida dos libertinos, sem deixar de lado restrições às orgias que eles foram lá para cometer:

Levantaremos todos os dias às dez da manhã. Nesta hora, os quatro fodedores que não estiverem de serviço durante a noite irão visitar os amigos, cada um levando consigo um garotinho; passarão sucessivamente de um aposento a outro. Agirão ao bel prazer e segundo os desejos dos amigos, embora nas preliminares os meninos servirão apenas para o prazer dos olhos, pois está decidido e acertado que as oito mocinhas somente perderão $o$ cabaço das conas no mês de dezembro, e o de seus cus, assim como o dos oito meninos, só serão 
sacrificados no decorrer de janeiro, e isto de modo a deixar a volúpia mais irritada pelo aumento de um desejo constantemente inflamado $e$ nunca satisfeito, estado que deve necessariamente levar a um certo furor lúbrico que os amigos gostam de provocar como uma das situações mais deliciosas da lubricidade. (Sade, 2006, p. 54, grifo meu)

É fácil perceber como a sensação de lubricidade, certamente ligada ao erotismo, é causada pela interposição de proibições e regras. Isso institui, ou melhor, revela - certo funcionamento paradoxal do direito. As regras, ao invés de funcionarem como freios às ânsias dos libertinos, são potentes estimulantes para sua ação. Se de uma norma se espera que desestimule a conduta, esta faz estimular pela proibição. Poderíamos dizer que o principal do prazer, ou, pelo menos boa parte dele, em desvirginar estes personagens não está no ato em si, mas sim em fazê-lo proibido para depois fugir à proibição, mesmo que isto se dê através dos modos institucionalizados - no tempo e observando os ritos combinados. Retomamos então o modo de funcionamento da transgressão, ela ultrapassa o interdito através de formas ritualizadas, mas jamais o inibe ou simplesmente o ignora. Sabemos, ainda, que o sentido e valor de cada ação é dada no jogo de interdito e transgressão. Devemos agora esclarecer um pouco melhor o funcionamento de cada termo desta relação, ou seja, explicar o que seria interdito para posteriormente entender melhor o que seria transgressão, lembrando sempre que o foco deste estudo se encontra no último.

Quem transgrede, transgrede algo. No caso, o objeto da transgressão é o interdito. Em uma perspectiva histórica, segundo Bataille, poderíamos notar a presença do interdito já desde a época do homem de neandertal (BATAILLE, 2013, p. 67-8), uma vez que sabemos que este enterrava seus mortos. Contudo, desde antes já notamos indícios de que os interditos atuavam ou estavam ao menos tomando forma. Isto porque pudemos encontrar ferramentas feitas pelo Australopitecos. A relevância deste achado arqueológico é o fato de demonstrar que aquele proto-homem já conhecia o trabalho; de algum modo, já buscava furtar-se à violência incessante da vida na natureza (BATAILLE, 2013, p. 64), por meio da racionalização de sua experiência e contato com o mundo. É este o sentido primordial do interdito. Não é de se estranhar, portanto, que os primeiros interditos de que temos notícia relacionaram-se à morte (BATAILLE, 2013, p. 65), como atestam as já citadas sepulturas dos neandertais.

Bataille nos mostra também que um dos interditos primordiais se refere à 
sexualidade. Isto poderia parecer em um primeiro momento contra intuitivo, já que os interditos em geral referem-se à violência; o que Bataille nos mostrará é uma cumplicidade entre morte $\mathrm{e}$ nascimento, que tem paralelo na entre sexo e violência. De acordo com ele, o ato sexual, dado seu caráter naturalmente ligado à atividade genésica, é necessariamente dotado de uma violência terrível. $\mathrm{Na}$ verdade, $\mathrm{o}$ ato sexual representa no limite a própria morte do sujeito que com ele se envolve. Ele nos comprova isto buscando aliar os dados objetivos da reprodução dos animais sexuados e assexuados com a experiência subjetiva própria do homem, a qual fica comprometida face à violência do sexo (BATAILlE, 2013, p. 128). Podemos compreender de um modo mais ou menos simples o que ele busca dizer quando nos propõe um ligeiro exercício de imaginação. Comecemos por pensar na mulher mais respeitável que possamos conceber. No momento do sexo torna-se ela, nas palavras do autor, uma cadela, sua personalidade tão respeitável, neste momento, morre (BATAILLE, 2013, p. 131). Mesmo que o argumento possa parecer, para nossa sensibilidade contemporânea, um tanto polêmico, o que importa é que fica bastante clara a relação entre sexo e violência; o ápice do ato sexual tem um caráter de naturalidade, animalidade, capaz de anular os aspectos propriamente humanos daquele que com ele se envolve.

Novamente, podemos verificar na obra do Marquês de Sade este aspecto violento da transgressão que permite ligar os interditos do sexo e do assassinato. Bataille, na mesma passagem referida acima, nos lembra como por vezes é necessário ligar ao sexo ideias de violência para que se atinja o ápice do gozo. Esta afinidade entre sexo e violência não é desconhecida das personagens do Divino Marques. Elas a todo o momento buscam adicionar ao sexo atos de crueldade de toda espécie, como uma forma de acrescentar à lubricidade. Por vezes, a violência atinge um nível tão grande que é capaz de causar sensações lubricas mesmo em que está a ela submetido. Em uma passagem emblemática, Justine, a defensora da religião e da piedade, sempre pronta a refutar e buscar furtar-se às maldades que muitas vezes poderiam melhorar-lhe sensivelmente a vida (SADE, 2013, p. 108), tem um orgasmo enquanto é estuprada por um casal de irmãos incestuosos que estão prestes a vivisseccionar sua amiga (SADE, 2013, p. 216). Moravia (in SADE, 2006, p. XVIII), considerando este trecho, busca mostrar como opera em Sade certo "método profanatório". Segundo ele, Justine é ao mesmo tempo a garota pura e uma putain 
(termo que, em Sade, como é de se esperar, tem conotação bastante positiva), ela consegue sentir prazer na própria profanação. Isso porque, dentro da cosmovisão sadeana, o vício é o substrato físico, corporal, que ancora o ser humano na natureza. A virtude, que Justine tanto professa, é apenas um redobro semântico da vida humana, que sempre sucumbe face aos imperativos do corpo. Se seguirmos o pensamento de Bataille, Justine morreu em certo sentido. Na medida em que a violência é a negação do que em nós é humano, a violência que a envolve e da qual ela participa, mesmo que involuntariamente, calou por um momento sua subjetividade dando livre curso a um gozo "animal".

A caracterização destes prazeres como "animais" ou "bestiais" não é gratuita. Bataille nota que de fato existe um caráter de animalidade neste tipo de sexualidade transgressora. Por meio do interdito, o homem se separa do animal, que não é capaz de se furtar ao mundo da morte e da violência. Porém, no momento da transgressão, reaproxima-se deste animal (BATAILLE, 2013, p. 107), mas não no modo de um simples retorno à natureza (BATAILLE, 2013, p. 108), senão no de um verdadeiro movimento dialético. $\mathrm{O}$ interdito, mesmo ultrapassado, não deixa de atuar, mas mantém-se enquanto negado. Certamente, não ocorreria se tratássemos apenas do retorno ao natural; a violência e a sexualidade que se fala aqui não é a animal, mas aquela de um "ser de razão que sucumbe" ao chamado de um fundamento ou substrato natural que serve de suporte fático para todo o mundo propriamente humano de significações culturais. Eis aqui um modo interessante de conceber o erotismo, uma atividade propriamente humana, mas que se aproxima por uma dialética entre interdito e transgressão da natureza. Como já dissemos, o que pretendemos mostrar aqui é a aproximação de Sade e Bataille por meio da noção de transgressão, agora, poderemos buscar esta relação com mais rigor ao olharmos em seu ponto fulcral, a concepção de natureza.

Devemos considerar que o esforço de Sade se insere no momento do ápice do iluminismo. Muitos autores anotaram um caráter eminentemente científico na obra de Sade. Ele teria investigado de forma sistemática e metódica o fenômeno da sexualidade humana. Teria concluído esse percurso encontrando uma fundamentação racional para explicar porque o que se convencionou chamar de crime era na verdade a ação moral por excelência. Apesar do fato de que o Divino Marquês escrevia obras literárias, não podemos ignorar o forte caráter argumentativo que se mostra para nós com clareza, de modo que poderíamos chamar, juntamente com 
Pierre Klossowski (in Sade, 2013, p. 9), suas obras de "romances de ideia". Isto fica perfeitamente claro na própria linguagem de Sade. O autor não tem interesse em excitar-nos ou nos entreter (BATAILLE, 2013, 219), ao menos durante a maior parte de seu texto; o que ele faz é descrever em pormenores os acontecimentos (SADE, 2013, p. 226), pratica uma observação de caráter quase científico dos atos sexuais de seus personagens (SADE, 2013, p. 469), extrai medidas (SADE, 2013, p. 221), posições exatas (ADORNO e HORKHEIMER, 2006, p. 76), busca descrever sensações do modo mais acurado possível (SADE, 2014, p. 60), e mesmo nos momentos de ápice do ato sexual não permite a seus sujeitos deixarem de falar (SADE, 2014, p. 71), inclusive de falar filosofia (SADE, 2014, p. 85-6).

Neste contexto, o que se vê é, portanto, uma busca argumentativa para fundamentar uma moral puramente racional, destituída de todo tipo de dogma. Neste sentido, o autor faz recurso à natureza. Tal tipo de consideração não era incomum em sua época, alguns nomes relevantes dentre os iluministas em geral buscaram na natureza uma base sobre a qual desenvolver a moral e a política (SADE, 2014, p. 221); o que é incomum em Sade é o conteúdo atribuído ao natural. Em um caráter mais geral, podemos dizer que para ele a natureza tinha essencialmente o sentido de "um princípio criador onisciente, que tem metas traçadas para suas criações", ela cumpre uma função análoga à de Deus para alguns sistemas filosóficos, o mais curioso, porém, é quando descemos ao nível do detalhe em tal concepção. Algumas passagens típicas dela podem ser encontradas em "Justine". Em uma primeira, Coeur-de-Fer expõe à heroína como a natureza se utiliza de crimes muitas vezes para atingir seus objetivos, o tirano deve cometer as ideias de atrocidade que se lhe sugerem pois "a voz da natureza lhe a sugeriu" (SADE, 2012, p. 51), todos os crimes seguem uma mesma lógica maior da natureza, a qual os utiliza com o fim de reestabelecer as situações que a ela são melhores. O que se quer mostrar é como Sade inova em sua concepção. O homem deixado a seus instintos é violento, mas isto não uma exclusividade da natureza humana. A natureza entendida de modo geral é o âmbito da violência, o homem violento apenas escuta sua voz, tira dela seus ensinamentos.

Inserido na obra "A Filosofia na Alcova" encontra-se um panfleto político chamado "Franceses, Mais um Esforço se Quereis ser Republicanos". Neste encontram-se expostas de modo um tanto mais sistemático algumas ideias políticas do Marques, inclusive referentes à natureza 
criminosa ou não do assassinato. Enquanto em um primeiro momento se nos afirma a falta de valor do homem perante a natureza, já que ele não custa a ela esforço algum ou ao menos nenhum esforço maior que o da geração de um animal comum, nesta passagem Sade ainda por cima nos lembra de como a natureza necessita da matéria que se encontra nos corpos para poder criar novos seres, de modo que a destruição é mais que sancionada, é necessária, é seu modus operandi. A violência, aqui pensada sob a forma do assassinato, é, portanto, mostrada como um bem que se faz à ordem natural das coisas (SADE, 2014, p. 161-2), fica comprovado que o crime não é imoral, nem ao menos amoral, irrelevante do ponto de vista da moralidade. Do ponto de vista de uma ética racional que busca seus fundamentos na natureza o crime é a ação moral por excelência, é um guia para a conduta humana. Estas são apenas algumas dentre tantas passagens que mostram a peculiar caracterização de Sade da natureza, um âmbito de violência desmesurada, destruição e gozo, no qual carrasco e vítima, tanto quanto homem e animal, são colocados como agrupamentos de matéria de igual valor, apenas aguardando o momento de seu retorno à natureza para serem reutilizados na produção de novos seres.
Uma vez que a natureza ordena a imoralidade e o crime podemos ainda dizer que nela o destrutivo tem mais valor que o construtivo, em suas leis o trabalho como o concebemos não tem lugar. Para Bataille, o trabalho é o âmbito da racionalidade utilitarista por excelência. $\mathrm{O}$ aspecto homogêneo da sociedade é caracterizado pelo homem trabalhador comum (BATAILLE, 1979, p. 65), enquanto que o heterogêneo é parte do mundo do sagrado, do dispêndio inútil (BATAILLE, 1979, p. 69), como praticado pela natureza. Basta nos lembrarmos dos discursos libertinos de Coeur-de-Fer, que faz a apologia do onanismo e da sodomia remetendo-se ao desperdício de forças e materiais que a natureza corriqueiramente propala (SADE, 2012, p. 45). Podemos assim dizer que o heterogêneo está no mundo da transgressão, sendo caracterizado por ser o intocável, objeto de interdito e desejos simultaneamente, fora das leis, etc., enquanto que o homogêneo, aquele que trabalha, é da ordem do interdito. Já ficou clara anteriormente a relação entre trabalho e interdito, conhecemos os interditos ao mesmo tempo em que entramos no mundo do trabalho, buscando furtar-nos à violência; o novo passo que tomamos agora é caracterizar o interdito como um âmbito da racionalidade, enquanto que a transgressão significa o inconsciente, o violento, o que também já foi mostrado. 
Assim, a oposição e relação dialética entre interdito e transgressão agora toma mais um sentido, trata-se de uma dualidade entre racionalidade, entendida como utilitarismo, e irracionalidade, aqui vista como o dispêndio. Assim fica claro como no mundo do interdito, que também é da natureza em certo sentido, o trabalho resta excluído e a destruição passa a ter mais valor aos olhos da natureza que a produção. Desta concepção, ambos os autores compartilham.

A afinidade entre racionalidade e interdito pode parecer em um primeiro momento conflitar com o trabalho de Sade. De início, quando o autor em vários pontos de sua obra mostra seus personagens, que poderíamos dizer de certo modo serem parte do mundo heterogêneo da transgressão, utilizando-se de modos racionais do discurso fílosófico e mesmo de aparatos técnicos para aumentar seu gozo. Não nos deixemos enganar por uma leitura superficial, os libertinos de Sade sentem um ódio fulminante pelo trabalho e pela produtividade. Em uma passagem interessante, um personagem escraviza Justine e a obriga a trabalhar junto com outras mulheres também escravas suas (SADE, 2012, p. 243), seu gozo surge justamente não no trabalho, mas na violência, principalmente em desvirtuar os mecanismos e modos de funcionamento internos do trabalho pelo uso da violência.
Poderia parecer que a confusão entre trabalho e prazer levaria a uma descaracterização da violência e da transgressão. Bataille nos explica que o que ocorre é justamente o oposto, uma descaracterização do trabalho e da racionalidade. Apesar de Roland, o personagem citado mais acima, obrigar Justine a trabalhar, sabemos que isto não era produtivo, tanto que posteriormente, quando sai do jugo de seu torturador, Justine trabalha com muito mais frutos sem ser violentada (SADE, 2012, p. 270). O que caracteriza a transgressão é seu aspecto de desmesura, seu excesso. Mesmo se o trabalho é utilizado dentro da atividade transgressiva, ele se descaracteriza por não ser útil (BATAILLE, 2013, p. 196), ao menos no sentido que se entende neste contexto da racionalidade.

Um caso ainda mais exemplar é a passagem em que Justine, após inocentemente tentar salvar um bebe da morte, é raptada por libertino cujo prazer é fazer engravidarem moças para após o parto matar seus filhos recém-nascidos. Para tornar viável a realização de suas lubricidades com a frequência necessária, ele criou uma máquina e todo um método, um verdadeiro procedimento terapêutico para aumentar a fertilidade de suas vítimas e garantir a fecundação com o mínimo de tentativas possíveis (SADE, 2013, p. 229). 
Se seus métodos funcionassem de fato, seria ele um nome relevante na medicina contemporânea, mas sendo seus estudos apenas parte de uma obra de ficção libertina o que cabe ressaltar é como ele tomou os modos de funcionamento típicos da razão utilitarista e científica ao ponto de desenvolver um dispositivo técnico razoavelmente complexo cujo único fim era satisfazer sua luxuria infernal. Do trabalho realizado por ele, pode-se dizer que perdeu suas características intrínsecas de racionalidade, de âmbito da interdição, e passou a servir ao mundo da transgressão.

Assim também se responde a uma segunda questão que o texto de Sade nos põe em relação à oposição entre racionalidade e transgressão. Esta se refere à própria forma narrativa escolhida pelo autor. Notamos mais acima como Sade faz um texto analítico, frio, em muitas passagens racional e argumentativo. Bataille define: é preciso "resignação para lê-1o" (BATAILLE, 2013, p. 219). Poderia parecer uma incongruência falar de transgressão, narrar uma violência. Bataille mesmo considera a violência como um silêncio, algo que a linguagem teima em negar e excluir da existência por causa de sua própria incompatibilidade, sem sucesso (BATAILLE, 2015, p. 215). Porém, ao pôr a brutalidade em palavras, Sade desvirtua a linguagem e a racionalidade assim como o excesso faz com o trabalho. Utilizando-se dos mecanismos lógicos que a frieza de sua narrativa lhe torna disponíveis aumenta o gozo (BATAILLE, 2015, p. 221), e consequentemente a violência, ao ponto de ser ela uma violência contra a própria razão. Como nota Pierre Klossowski (1984, p. 17-8), ao utilizar-se de categorias lógicas que constituem o próprio ato de escrever para justificar o ilógico, o ateísmo absoluto que leva à prostituição universal, Sade torna a razão contraditória, assim efetuando uma crítica a ela. Bataille (2013, p. 222) reconhece isto como o inserir na consciência o seu oposto. Como logo acima dissemos, deste modo fica a própria consciência desvirtuada pelo regime de excesso ao qual é submetida. Com base nestas considerações respondem-se às incongruências que parecem surgir na obra de Sade quando fazemos uma leitura primeira, o uso da razão e da linguagem tanto pelo autor quanto pelos personagens não descaracteriza a extrema violência da obra, serve sim para desvalorizar uma razão que passa a ser obrigada a trabalhar em sentido oposto ao que normalmente lhe cabe.

Respondidas estas objeções que se poderiam fazer a Sade, fica ainda mais clara a proximidade entre o autor e Bataille no que tange à noção de transgressão. Em ambos se trata da aproximação com a natureza, mas entendida esta em um 
sentido próprio, como âmbito do dispêndio, da crueldade e da irracionalidade dentre outros adjetivos mais que a qualifiquem.

Deste modo, o que buscamos Referências Bibliográficas afirmar por meio deste humilde trabalho, e que consideramos razoavelmente exposto, é que o ponto central da proximidade entre Bataille e Sade é a concepção da natureza à qual o movimento transgressor reaproxima o homem. Partindo dela, ambos vão mostrar como o homem, dela excluído, por vezes busca reaproximar-se de seu ponto de partida, resultando assim em grandes orgias de destruição, como a festa do Potlatch, uma celebração dentre os índios americanos na qual os lideres buscavam humilhar uns aos outros destruindo seus bens, matando seus escravos e oferecendo grandes e luxuriosos banquetes e presentes, os quais constituíam a economia do desperdício desses chefes, que por seu caráter sobrenatural pertenciam ao mundo do heterogêneo (HABERMAS, 2007, p. 229). Seria possível inclusive que o Marquês tomou um passo ainda mais ousado ao, depois de reconhecer a ligação entre natureza e irracionalidade, querer ainda aproximar a razão destes termos e assim efetuar sua crítica. Sade não era um teórico, mas como Bataille (2013, p. 223) diz, sem seu trabalho, jamais teríamos chegado ao conhecimento das coisas do erotismo e da transgressão. 
ROCHE, Geoffrey. Black Sun:

Bataille on Sade in Janus Head, vol. 9, $\mathrm{n}^{\circ}$

1. Amherst: Trivium Publications. 2006.

SADE, Donatien Alphonse

Françoise de. A Filosofia na Alcova. São

Paulo: Editora Iluminuras. 2014.

_ _ Justine. Milão:

Mondolibri. 2012.

; La Nuova Justine. Parma:

Ugo Guanda Editore. 2013.

; Os 120 Dias de Sodoma

ou A Escola da Libertinagem. São Paulo:

Editora Iluminuras. 2006. 